\title{
Obezite Cerrahisi Sonrası Semptomatik Kolelitiazis Gelişme Sıklığı ve Cerrahi Tedavide Zamanlama
}

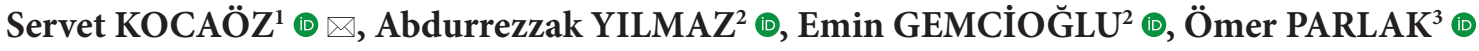 \\ ${ }^{1}$ Ankara Şehir Hastanesi, Genel Cerrahi Anabilim Dalı, Ankara, Türkiye \\ ${ }^{2}$ Ankara Şehir Hastanesi, İç Hastalıkları Anabilim Dalı, Ankara, Türkiye \\ ${ }^{3}$ Ankara Yıldırım Beyazıt Üniversitesi, Tıp Fakültesi, Genel Cerrahi Anabilim Dalı, Ankara, Türkiye
}

Bu makaleye yapılacak atıf: Kocaöz S, Yılmaz A, Gemcioğlu E, Parlak Ö. Obezite Cerrahisi Sonrası Semptomatik Kolelitiazis Gelişme Sıklığı ve Cerrahi Tedavide Zamanlama. Türk Diyab Obez 2020;3: 244-248.

\begin{abstract}
ÖZ
Amaç: Dünya'da 18 yaş ve üzeri yetişkinlerin \%13'ü obez olup, obeziteye komorbid hastalıklar da artmaktadır. Obezite cerrahisi sonrası normal kiloya ulaşan hastalarda komorbid hastalıklarda iyileşme gözlenmektedir. Obezite ile safra kesesinde taş oluşumu insidansı artmaktadır. Obezite cerrahisi sonrasında yeni taş gelişimi de yüksek oranlarda bildirilmektedir. Bu çalışmada Laparoskopik Sleeve Gastrektomi (LSG) ameliyatı sonrası gelişebilecek safra kesesi taşı ve/veya komplikasyonlarının değerlendirilmesi amaçlanmıştır.

Gereç ve Yöntemler: Ankara Atatürk Eğitim ve Araştırma Hastanesinde Ocak 2013 ile Aralık 2016 yılları arasında LSG ameliyatı yapılan 68 hastanın dosyası retrospektif olarak incelendi.

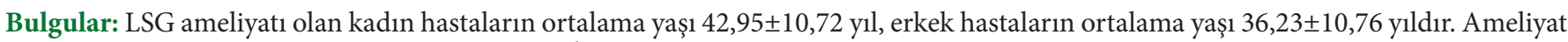
öncesi kadın hastalarda vücut kütle indeksi (VKİ) ortalaması 45,26 $\pm 3,58 \mathrm{~kg} / \mathrm{m}^{2}$, erkeklerde 47,58 $\pm 7,74 \mathrm{~kg} / \mathrm{m}^{2} \mathrm{iken}$ ameliyattan iki yıl sonrasında VKİ ortalaması kadınlarda $27,18 \pm 2,80 \mathrm{~kg} / \mathrm{m}^{2}$, erkeklerde $27,92 \pm 3,79 \mathrm{~kg} / \mathrm{m}^{2}$ ye düştügü saptandı (p<0,001). LSG operasyonu geçiren hastaların 17(\%31)'sinde safra kesesi taşı veya çamuru saptandı. Postoperatif safra kesesi taşı gelişen hastalardan birisinde $(\% 5,88)$ akut kolesistit geliştiği bulundu. LSG ameliyatı sonrası hastalar kilo kaybı açısından karşılaştırıldıklarında safra taşı gelişen ve gelişmeyenler arasında istatistiksel olarak anlamlı bir farklılık saptanmadı ( $\mathrm{p}=0,065)$.

Sonuç: LSG ameliyatı yapılacak hastalardan semptomatik kolelitiazis şikayeti olmayan hastalara laparoskopik kolesistektomi (LK) yapılması gerekmedi. LSG ameliyatı sonrası safra kesesinde yeni taş gelişmesi yüksek oranda bulundu. Bununla birlikte bu taşlar erken dönemde semptom vermediği için LSG hastalarının düzenli kontrolünün yapılmasının semptomatik kolelitiazis insidansını azaltacağı kanaatindeyiz.
\end{abstract}

Anahtar Sözcükler: Morbid obezite, Laparoskopik sleeve gastrektomi, Safra kesesi taşları, Kolesistektomi

\section{Prevalence of Symptomatic Cholelithiasis After Obesity Surgery and Timing of Surgical Treatment}

\begin{abstract}
Aim: 13\% of adults are 18 years old and over, and comorbid diseases of obesity are on the increase in the World. Patients that reach standard weight after bariatric surgery show recovery in comorbid diseases. Gallbladder stone incidence rate increases with obesity. Development of stone after bariatric surgery is known to be on higher levels, as well. The objective of this study is to analyze the gallbladder stone and/or complications that may develop after Laparoscopic Sleeve Gastrectomy (LSG) surgery.

Material and Methods: The medical files of 68 patients were retrospectively analyzed, who underwent LSG surgery between January 2013 and December 2016 in Ankara Atatürk Training and Research Hospital.
\end{abstract}


Results: The age average of female patients that underwent LSG surgery is $42.95 \pm 10.72$, while it is $36.23 \pm 10.76$ for male patients. While the mean BMI (Body Mass Index) of female and male patients were respectively $45.26 \pm 3.58 \mathrm{~kg} / \mathrm{m}^{2}$ and $47.58 \pm 7.74 \mathrm{~kg} / \mathrm{m}^{2}$, this mean was found that BMI levels decreased to $27.18 \pm 2.80 \mathrm{~kg} / \mathrm{m}^{2}$ for female patients and $27.92 \pm 3.79 \mathrm{~kg} / \mathrm{m}^{2}$ for male patients ( $\left.\mathrm{p}<0.001\right) .17(31 \%)$ of the patients, who underwent LSG surgery suffered from gallbladder stone or sludge. Acute cholecystitis was found in one (5.88\%) of the patients who developed post-operative gallbladder stones. When the patients after LSG surgery were compared in terms of weight loss, no statistically significant difference was found between those with and without gallstones $(\mathrm{p}=0.065)$.

Conclusion: Laparoscopic cholecystectomy (LC) was not required in patients who did not have symptomatic cholelithiasis. The rate of developing gallbladder stone after LSG surgery was found to be high. However, since these stones do not show any symptoms in the early period, we think that regular control of LSG patients will decrease the incidence of symptomatic cholelithiasis.

Key Words: Morbid obesity, Laparoscopic sleeve gastrectomy, Gallstones, Cholecystectomy

\section{GIIRIŞ}

Dünya Sağlık Örgütü (WHO), 2016 yılında Dünya'da 18 yaş ve üzeri yetişkinlerin \%13'ünün yani 650 milyondan fazla yetişkinin obez olduğunu bildirmektedir (1). Türkiye İstatistik Kurumu (TÜİK) 2016 verilerine göre Türkiye'de 15 yaş ve üzeri bireylerde erkeklerin $\% 15,2$ 'si, kadınların $\% 23,9$ 'unun obez olduğu tespit edilmiştir (2).

Obezitenin tedavisinde diyet, egzersiz ve medikal tedavi ile baş edilemediğinde cerrahi tedavi diğer bir seçenektir. Bariatrik cerrahide laparoskopik sleeve gastrektomi (LSG) günümüzde en sık uygulanan yöntem hâlini almıştır (3). LSG ameliyatı sonrası Obez hastaların normal kilolara ulaşması ile diyabet (DM), hipertansiyon (HT), koroner arter hastalığı, karaciğer yağlanması ve uyku apnesi sendromu gibi obezitenin neden olduğu komorbiditeler iyileşebilir veya düzelebilir $(4,5)$. LSG ameliyatı, Roux-en-Y gastrik bypass ile karşılaştıııldığında morbidite ve mortalite daha az görülmektedir (6). LSG etkili ve güvenilir bir yöntem olmakla birlikte hasta ameliyat sonrası diyetine dikkat etmez ise tekrar kilo almaktadır. Hastalarda gastroözefagial reflü yakınması sık görülmektedir (7).

Kolelitiazis, genel nüfusta $\% 5$ oranında görülürken, obez popülasyonda $\% 45$ oranlarına kadar artmaktadır $(8,9)$. Obezite cerrahisi sonrası kısa zamanda hızlı kilo kaybı, orijinal ağırlığın \%25’inden daha fazla kilo kaybı, ameliyat sonrası safra kesesi taşı oluşumuna neden olmaktadır (10). Safra kesesinde kolesterol seviyesindeki artış ve safra müsin konsantrasyonunda doygunluk nedeniyle taş geliştiği bildirilmiştir (11). Asemptomatik safra kesesi taşları ameliyattan 6-12 ay sonra semptomatik hâle gelebilmektedir.

Obezite cerrahisi sonrası safra kesesinde taş olan hastaların \%30-52'sinde semptomlar gözükmekte ve \%2-3 oranında hastada ciddi komplikasyon görüldüğü bildirilmiştir (12). $\mathrm{Bu}$ nedenle, araştırmamızda hastaların LSG ameliyatından iki yıl sonrası izlemlerinde kilolarının kalıcı olup olmadığı ve LSG sonrası gelişebilecek safra kesesi taşı ve/veya komplikasyonlarının değerlendirilmesi amaçlandı.

\section{GEREÇ ve YÖNTEMLER}

Ankara Atatürk Eğitim ve Araştırma Hastanesinde Ocak 2013 ile Aralık 2016 yılları arasında LSG ameliyatı yapılan VKI $40 \mathrm{~kg} / \mathrm{m}^{2}$ yi aşan 68 hasta da safra kesesi taşı hastalığı geçirme insidansını belirlemek amacıyla hastane arşivinden hasta dosyaları incelenerek analizi yapıldı.

Çalışma için Yıldırım Beyazıt Üniversitesi Tıp Fakültesi Klinik Araştırmalar Etik Kurulu'nun 07.05.2018 tarih ve 107 Sayılı Kurul Kararı ile onay alınarak gerçekleştirilmiştir.

Hastaların ameliyat raporu, ameliyat öncesi, sonrası ve takip ultrasonografi raporları, patoloji raporları, biyokimyasal tetkikleri, tekrar ameliyat olmuşsa ameliyat raporu ve başka girişimsel işlem geçirmişse raporları retrospektif olarak incelendi.

Araştırmadan elde edilen veriler, SPSS (25.0, IBM Corp., Armonk, NY) programı kullanılarak analiz edildi. Araştırmada tanımlayıcı istatistik olarak kategorik veriler için sayı (n), yüzde (\%), sayısal veriler için ortalama \pm standart sapma verildi. Verilerin normal dağılıp dağılmadığına Kolmogorov-Smirnov testiyle bakıldı. LSG ameliyatı öncesi ve sonrası hastaların VKİ değerleri $t$ testi (paried-samples t test) kullanılarak karşılaştırıldı. Safra taşı gelişmesi ile ameliyat öncesi ve sonrası VKİ değerleri arasında anlamlı bir fark olup olmadığı yine bu test kullanılarak araştırıldı.

\section{BULGULAR}

Laparoskopik sleeve gastrektomi ameliyatı yapılan hastalardan 55'i (\%81) kadın, 13’u (\%19) erkek hastaydı. Kadın hastaların en küçük yaşta olanı 22 yaşında, en büyük yaşta olanı 64 yaşındaydı. Kadın hastaların ortalama yaşı $42,95 \pm 10,72$ yıldı. Erkek hastaların en küçük yaşta olanı 21 yaşında, en büyük yaşta olanı 57 yaşındaydı. Erkek hastaların ortalama yaşı $36,23 \pm 10,76$ yıldı. Ameliyat öncesi kadınlarda VKİ ortalaması 45,26 $\pm 3,58 \mathrm{~kg} / \mathrm{m}^{2}$ (en düşük VKİ: $41 \mathrm{~kg} / \mathrm{m}^{2}$, en yüksek VKİ:56 kg/m²) olarak bulundu. Ameliyat öncesi erkeklerde VKİ ortalaması 47,58 $\pm 7,74 \mathrm{~kg} / \mathrm{m}^{2}$ (en düşük VKİ:41 kg/m², en yüksek VKİ: $62 \mathrm{~kg} / \mathrm{m}^{2}$ ) olduğu tespit edildi 
(Tablo 1). Ameliyattan iki yıl sonra hastalar tekrar kontrole çağırılarak VKİ ölçümü yapıldı. Ameliyat sonrası kadınlarda VKİ ortalaması $27,18 \pm 2,80 \mathrm{~kg} / \mathrm{m}^{2}$, erkeklerde VKİ ortalamasi $27,92 \pm 3,79 \mathrm{~kg} / \mathrm{m}^{2}$ olarak bulundu $(p<0,001)$.

Çalışmamızda yer alan hastalardan üç tanesi LSG ameliyatı öncesi LK operasyonu geçirdiği saptandı. Safra kesesinde taş olan 13 hastadan bir hastaya ve yine safra kesesinde polip olan iki hastaya LSG operasyonu esnasında LK ameliyatı yapıldı. Safra kesesinde semptom vermeyen taşı olan $12(\% 92,31)$ hastaya sadece LSG operasyonu yapildı. Safra kesesinde semptom vermeyen taşı olan $1(\% 8,33)$ hastaya LSG'den sonra (ilk 6 aylık sürede) LK ameliyatı yapılması gerekti. LSG operasyonu geçiren diğer 17 (\%31) hastanın iki yıllık izleminde yeni safra kesesi patolojisi saptandı (Tablo 2).

Ameliyat sonrası anastomoz kaçağı gibi önemli bir komplikasyon saptanmadı. Ameliyat öncesi safra kesesinde taş olmayan bir $(\% 5,88)$ hastada LSG ameliyatından 4 ay sonra akut kolesistit tablosu gelişti ve acil operasyona alındı. LSG ameliyatı sonrası hastalar kilo kaybı açısından karşılaştırıldıklarında safra taşı gelişen ve gelişmeyenler arasında istatistiksel olarak anlamlı bir farklılık saptanmadı $(\mathrm{p}=0,065)$.

Ameliyat öncesi safra kesesinde taş olan üç hastaya LSG ameliyatından 3-6 ay sonra biliyer kolik şikayetleri nedeniyle ikincil olarak LK ameliyatı gerçekleştirildi. Hiçbir şikayeti olmayan hastalara USG tetkiki yapıldığında, yedi hastanın safra kesesinde çamur, dokuz hastanın safra kesesinde milimetrik taş tespit edildi. Gastroözefagial reflü (GÖR) şikayeti olan altı hastaya ursodeoksikolik asit preparatı başlandı. $\mathrm{Bu}$ hastalardan ikisinin ultrasonografisinde safra kesesinde milimetrik birkaç adet taş tespit edildi. $\mathrm{Bu}$ hastaların düzenli hekim kontrolüne gitmediği ve diyetine uymadıkları tespit edildi. Yüksek kalorili içecekler, salçalı yiyecekler, çikolata vb. aşırı tüketimi nedeniyle bu altı hastanın GÖR şikayetlerinin olduğu ve tekrar kilo aldıkları saptand 1 (VKİ' de $4-6 \mathrm{~kg} / \mathrm{m}^{2}{ }^{2} l i k$ atış).

Araştırmamızda süre ortalama 1024 gün olarak gerçekleşti. Mortalite saptanmadi.

\section{TARTIŞMA}

Araştırmamızda laparoskopik sleeve gastrektomi ameliyatı öncesi morbid obez olan hastalarm (15) \%23,81'inde safra kesesi taşı veya polibi saptand. Morbid obez olan üç hastamız laparoskopik sleeve gastrektomi operasyonu öncesi LK operasyonu geçirdiği belirlendi. Safra kesesinde semptom vermeyen taşı olan bir $(\% 8,33)$ hastaya LSG'den kısa zaman sonra LK ameliyatı yapılması gerekti. Bu oran literatürle uyumlu bulunmuştur (12). Obezite Cerrahisi öncesi safra kesesinde taş olan hastaların ameliyat esnasında, ameliyat sonrası safra kesesi taşı olan hastaların en uygun zamanda kolesistektomi operasyonunun yapılması önerilmektedir. LSG esnasında LK ameliyatı yapılması operasyon süresini uzatsa bile hastanede kalı̧s süresi ve morbiditeyi azaltacağı bildirilmiştir (13). Yaptığımız incelemede LSG sonrası safra kesesinde taş oluşumunun özellikle ilk yıl içerisinde geliştiği tespit edildi. LSG ameliyatı geçiren 17 (\%31) hastada yeni safra kesesi taşı veya çamuru gelişimi saptandı. Hastalarımızın ilk altı aylık sürede aylık 3-6 kg kilo verdikleri tespit edildi. Hızlı kilo kaybı ile safra kesesinde taş oluşumunda artışı ilişkilendiren çalışmalar bulunmaktadır $(14,15)$. Bizim çalışmamızda hızlı kilo kaybı ile safra kesesi taşı gelişimi arasında anlamlı bir bulgu saptanmadı $(\mathrm{p}=0,065)$. LSG ameliyatı sonrası hızlı kilo kaybının erken ve geç dönemde safra kesesi ve safra yollarında taş gelişmesi arasında ilişki saptanmadığı bildirilen çalışmalar da bulunmaktadır (16). Bir hastaya akut kolesistit nedeniyle LK ameliyatı uygulandı. İki hastada ise reflü ile birlikte biliyer kolik semptom-

Tablo 1: Sleeve gastrektomi öncesi ve sonrası obez bireylerin özellikleri

\begin{tabular}{lcccc}
\hline & Hasta Sayısı & LSG Öncesi & LSG Sonrası & $p$ Değeri \\
\hline Kadın VKI $\left(\mathrm{kg} / \mathrm{m}^{2}\right)$ & 55 & $45,26 \pm 3,58$ & $27,18 \pm 2,80$ & $<0,001$ \\
\hline Erkek VKİ $\left(\mathrm{kg} / \mathrm{m}^{2}\right)$ & 13 & $47,58 \pm 7,74$ & $27,92 \pm 3,79$ & $<0,001$ \\
\hline
\end{tabular}

Paried-Samples T test

Tablo 2: LSG operasyonu geçiren hastalardan safra taşı gelişen ve gelişmeyenlerin VKİlerinin karşılaştırılması

\begin{tabular}{lccc}
\hline & Safra Taşı Olan Grup & Safra Taşı Olmayan Grup & p Değeri \\
\hline LSG Cerrahisi Öncesi VKİ & $45,21 \pm 4,51$ & $44,04 \pm 2,05$ & 0,522 \\
\hline LSG Cerrahisi Sonrası VKİ & $27,47 \pm 2,87$ & $28,18 \pm 2,81$ & 0,332 \\
\hline Toplam Kilo Kaybı VKİ & $17,98 \pm 4,36$ & $16,86 \pm 2,56$ & 0,065 \\
\hline
\end{tabular}

Paried-Samples T test 
ları saptandı. LSG sonrası safra kesesi patolojisi saptanan hastaların semptomatik olma oranı düşük kalmaktadır. Bu nedenle rutin LSG ameliyatı ile birlikte LK ameliyatı yapılması önerilmemektedir $(17,18)$. LSG sonrası rutin ursodeoksikolik asit preparatı kullanılmasının safra kesesi ve safra yollarındaki taş gelişimini azalttığı bildirilmektedir (19). Ancak biz operasyon sonrası kontrollerde USG'de taş tespit edilen olgularda ursodeoksikolik asit preparatı kullanılmasını önermekteyiz. LSG obezite oldukça güvenilir, etkili, ciddi komplikasyonları olmayan ve operasyon sonrası hastalarca kolay tolere edilen bir cerrahi tekniktir. Araştırmamızda LSG operasyonu öncesinde veya sonrasinda safra kesesinde taş saptanan hastalara kolesistektomi yapılmasına gerek olmadığı, sadece semptomatik olan hastalara ameliyat esnasinda veya en uygun zamanda laparoskopik kolesistektomi yapılmasının uygun olacağını düşünmekteyiz.

Ameliyat öncesi safra kesesinde taş olan hastalarda, LSG sonrası safra kesesi taşına bağlı semptomların görülme oranı düşük olarak saptandı. LSG ameliyatı sonrası safra kesesinde yeni taş gelişme oranı yüksek olarak bulundu. Ancak semptomatik olma oranı düşüktü. İlaveten, LSG ameliyatı sonrası safra taşı gelişmesi ile verilen kilo arasında anlamlı bir ilişki saptanmadı. LSG sonrası gelişen safra kesesi taşlarının erken dönemde semptomatik bulgu verme oranı düşük oranda görüldüğü saptandı. Bu nedenle LSG operasyonu sonrası hastalara altı ayda bir USG tetkikinin de yapıldı $\breve{g}_{1}$ düzenli kontroller yapılmalıdır. LSG operasyonu öncesinde veya sonrasında safra kesesinde taş saptanan hastalara kolesistektomi yapılmasına gerek olmadığı, sadece semptomatik olan hastalara kolesistektomi yapılmasının uygun olacağ sonucuna varıldı.

\section{Etik Kurul Onayı}

Çalışma Yıldırım Beyazıt Üniversitesi Tıp Fakültesi Klinik Araştırmalar Etik Kurulu'nun 07.05.2018 tarih ve 107 Sayll Kurul Kararı ile gerçekleștirilmiștir.

\section{Çıkar Çatışması}

$\mathrm{Bu}$ araştırma ve yazıda yazarlar arasında bir çıkar çatışması bulunmamaktadır.

Finansal Destek

Finansal bir destek bulunmamaktadır.

Yazarların Makaleye Katkı Beyanı

Yazarlar eşit katkıda bulunmuşlardır.

\section{Hakem Değerlendirmesi}

Kör hakemlik süreci yayınlanmaya uygun bulunmuş ve kabul edilmiştir.

\section{KAYNAKLAR}

1. World Health Organization. Obesity and overweight (Internet). (2018 Feb 16, (cited 2018 August 30), http:// www.who.int/news-room/fact-sheets/detail/obesity-andoverweight.)

2. Republic of Turkey Ministry of Health. The Ministry of Health of Turkey, health statistics year book 2016. Ankara: SB-SAGEM-2017; (Cited 2018 August 30, http://ohsad.org/ wp-content/uploads/2017/12/13160.pdf.)

3. Kiriakopoulos A, Varounis C, Tsakayannis D, Linos D. Laparoscopic sleeve gastrectomy in morbidly obese patients. Technique and short term results. Hormones (Athens). 2009;8(2):138-143.

4. Eisenberg D, Bellatorre A, Bellatorre N. Sleeve gastrectomy as a stand-alone bariatric operation for severe, morbid, and super obesity. JSLS. 2013;17(1):63-67.

5. Al Zabadi H, Daqour A, Hawari A, Hasouni J. Short-term outcomes of laparoscopic sleeve gastrectomy among obesity patients in the Northern West Bank: A retrospective records review. BMC Res Notes. 2014;7:85.

6. Young MT, Gebhart A, Phelan MJ, Nguyen NT. Use and outcomes of laparoscopic sleeve gastrectomy vs laparoscopic gastric bypass: Analysis of the american college of surgeons NSQIP. J Am Coll Surg. 2015;220(5):880-885.

7. Våge V, Sande VA, Mellgren G, Laukeland C, Behme J, Andersen JR. Changes in obesity-related diseases and biochemical variables after laparoscopic sleeve gastrectomy: A two-year follow-up study. BMC Surg. 2014;14:8.

8. Dittrick GW, Thompson JS, Campos D, Bremers D, Sudan D. Gallbladder pathology in morbid obesity. Obesity Surgery. 2005;15(2):238-242.

9. Eleni S, Dimitris Z, Eleni Z, Dimitris P, Ourania P, Georgia $\mathrm{K}$, George T. Complicated gallstones after laparoscopic sleeve gastrectomy. Hindawi Publishing Corporation Journal of Obesity. 2014;2014:468203.

10. Li VK, Pulido N, Fajnwaks P, et al. Erratum to "Predictors of gallstone formation after bariatric surgery: A multivariate analysis of risk factors comparing gastric bypass, gastric banding, and sleeve gastrectomy". Surgical Endoscopy. 2009;23(7):1645.

11. Quesada BM, Kohan G, Roff HE, Canullan CM, Chiappetta Porras LT. Management of gallstones and gallbladder disease in patients undergoing gastric bypass. World J Gastroenterol. 2010;16:2075-2079.

12. Shiffman ML, Sugerman HJ, Kellum JM, Brewer WH, Moore EW, "Gallstone formation after rapid weight loss: a prospective study in patients undergoing gastric bypass surgery for treatment of morbid obesity," The American Journal of Gastroenterology, vol. 86, no. 8, pp. 1000-1005, 1991. 
13. Coşkun H, Hasbahçeci M, Bozkurt S, Çipe G, Malya FÜ, Memmi $\mathrm{N}$ et al. Is concomitant cholecystectomy with laparoscopic sleeve gastrectomy safe? Turk J Gastroenterol. 2014;25(6):624-627.

14. Erlinger S. Gallstones in obesity and weight loss. Eur J Gastroenterol Hepatol. 2000;12(12):1347-1352.

15. Iglézias Brandão de Oliveira C, Adami Chaim E, da Silva BB. Impact of rapid weight reduction on risk of cholelithiasis after bariatric surgery. Obes Surg. 2003;13(4):625-628.

16. Manatsathit W, Leelasinjaroen P, Al-Hamid H, Szpunar $\mathrm{S}$, Hawasli A. The incidence of cholelithiasis after sleeve gastrectomy and its association with weight loss: A two-centre retrospective cohort study. Int J Surg. 2016;30:13-18.
17. Li VK, Pulido N, Martinez-Suartez P, Fajnwaks P, Jin HY, Szomstein S, Rosenthal RJ. Symptomatic gallstones after sleeve gastrectomy. Surg Endosc. 2009;23(11):2488-2492.

18. Hasan MY, Lomanto D, Loh LL, So JBY, Shabbir A. Gallstone disease after laparoscopic sleeve gastrectomy in an asian population-what proportion of gallstones actually becomes symptomatic? Obes Surg. 2017;27(9):2419-2423.

19. Abdallah E, Emile SH, Elfeki H, Fikry M, Abdelshafy M, Elshobaky A et al. Role of ursodeoxycholic acid in the prevention of gallstone formation after laparoscopic sleeve gastrectomy. Surg Today. 2017;47(7):844-850. 